\title{
Ustekinumab in chronic immune-mediated diseases: a review of long term safety and patient improvement
}

This article was published in the following Dove Press journal:

Patient Preference and Adherence

25 April 2013

Number of times this article has been viewed

\author{
Éric Toussirot ${ }^{1-4}$ \\ Fabrice Michel $^{5}$ \\ Matthieu Béreau ${ }^{6}$ \\ Delphine Binda ${ }^{1,7}$ \\ 'Clinical Investigation Center - \\ Biotherapy CBT-506, University \\ Hospital of Besançon, Besançon, \\ France; 'Department of Rheumatology, \\ University Hospital of Besançon, \\ Besançon, France; ${ }^{3}$ Department of \\ Therapeutics, University of Franche- \\ Comté, Besançon, France; ${ }^{4}$ Equipe \\ d'Acceuil 4266 Pathogens and \\ Inflammation, Structure Fédérative de \\ Recherche-Fédération de Recherche \\ 4234, University of Franche-Comté, \\ Besançon, France; ${ }^{5}$ Department of \\ Physical Medicine and Rehabilitation, \\ University Hospital of Besançon, \\ Besançon, France; ${ }^{6}$ Department \\ of Neurology, University Hospital \\ of Besançon, Besançon, France; \\ ${ }^{7}$ Institut National de la Santé et de \\ la Recherche Médicale Unité Mixte \\ de Recherche 1098, Blood Transfusion \\ Center, Besançon, France
}

\begin{abstract}
Ustekinumab is a fully human monoclonal antibody targeting the common p40 subunit shared by interleukin (IL)-12 and IL-23. Ustekinumab prevents the interaction of IL-12 and IL-23 with their cell surface receptors, and thus blocks T helper (Th)-1 IL-12 and Th-17 IL-23 inflammatory pathways. Ustekinumab has been evaluated in the treatment of various chronic immune-mediated diseases including, psoriasis, psoriatic arthritis, Crohn's disease, and multiple sclerosis. It led to a rapid and durable improvement in psoriasis area and severity index in patients with moderate to severe psoriasis. Ustekinumab also improved joint symptoms of psoriatic arthritis. Results in Crohn's disease were more mitigated, albeit with a symptomatic improvement in patients refractory to tumor necrosis factor- $\alpha$ inhibitors. Ustekinumab did not reduce the number of magnetic resonance imaging brain lesions in multiple sclerosis. The most common adverse events to have been observed during clinical trials are mild in intensity, and include respiratory tract infections, nasopharyngitis, headaches, and injection site reactions. A pooled analysis of clinical trial data indicated no specific patterns of infection or malignancy under long-term ustekinumab administration. Ustekinumab is easy to use, has a comfortable therapeutic regimen, improves quality of life in patients, and thus appears to be an attractive biological treatment that is adapted and accepted by patients with moderate to severe psoriasis.
\end{abstract}

Keywords: IL-23, psoriasis, autoimmune diseases, quality of life

\section{Introduction}

Chronic inflammatory or immune-mediated diseases (IMDs) include different conditions that share common pathophysiological pathways, such as a genetic background, deregulation of the immune balance, and the involvement of a wide range of soluble mediators that drive inflammation, namely cytokines, chemokines, and growth factors. The most common IMDs include psoriasis, Crohn's disease (CD), multiple sclerosis (MS), and chronic arthritis such as psoriatic arthritis (PsA). The treatment approach for these different conditions is now based on control of the mediator(s) that play a major role in the disease pathogenesis. In this regard, targeting circulating tumor necrosis factor (TNF)- $\alpha$ has been shown to improve psoriasis, PsA, ${ }^{1}$ and CD. ${ }^{2}$

Interleukin (IL)-17 has emerged as a new and major contributor to different IMDs, especially rheumatoid arthritis, ${ }^{3}$ psoriasis and PsA, CD, and MS. $.{ }^{4,5} \mathrm{IL}-17$ is produced by the specific T-cell subset $\mathrm{T}$ helper (Th)-17, which is under the influence of IL-23, a cytokine belonging to the IL-12 family. ${ }^{5-7}$ Ustekinumab is a monoclonal antibody developed in the treatment of autoimmune diseases and targeting the p40 subunit common to IL-12 and IL-23.,8-10 It is currently available for the treatment of psoriasis and under development for the treatment of PsA and CD. ${ }^{10,11}$ This article will review
Correspondence: Éric Toussirot Clinical Investigation Center - Biotherapy CBT-506, University Hospital of Besançon, 25000 Besançon, France Tel +33381218790 Fax +33381218522

Email etoussirot@chu-besancon.fr 
the clinical efficacy and safety data on ustekinumab in the treatment of psoriasis, PsA, and CD. Results of the use of ustekinumab in the treatment of MS are also briefly discussed. This new biological agent administered for the long term in these chronic diseases opens new horizons in terms of quality of life for patients with chronic IMD.

\section{IL-I 2, IL-23, IL-I 7, and the IL-23/Th- I 7 pathway}

IL-23 is a member of the IL-12 family of cytokines that also includes IL-12, IL-22, IL-27, and IL-35. ${ }^{12}$ This cytokine family is associated with the generation of Th- 1 cells and the production of IL-12, stimulating innate immunity as well as the development of adaptive immunity and production of interferon (IFN)- $\gamma \cdot{ }^{13}$ IL-23 is a heterodimeric protein composed of a unique p19 subunit (IL-23p19) associated with a p40 subunit. p40 is also a component of IL-12 (IL-12p40), and this subunit is thus common to IL-12 and IL-23 (IL-12/23p40) (Figure 1). The formation of biologically active IL-23 requires the synthesis of both IL-23p19 and IL-12p40. IL-12 and IL-23 bind to the $\beta 1$ receptor (IL-12R $\beta 1$ ) of T cells and natural killer (NK) cells. The IL-12 receptor is composed of IL-12R $\beta 1$ and IL-12R $\beta 2$, while the receptor for IL-23 is formed by the association of IL-12R $\beta 1$ with another subunit (IL-23R). IL-23 binds to IL-23R and IL-12R $\beta 1$, but not to IL-12R $\beta 2 .^{13-15}$ The major source of IL-23 is different types of antigen-presenting cells such as activated dendritic cells, monocytes and macrophages. IL-12 is a heterodimer of IL-12p40 and IL-12p35, a subunit unique to IL-12. IL-12 induces the differentiation of naïve CD4+ T cells into IFN- $\gamma$ producing Th- 1 cells. The major

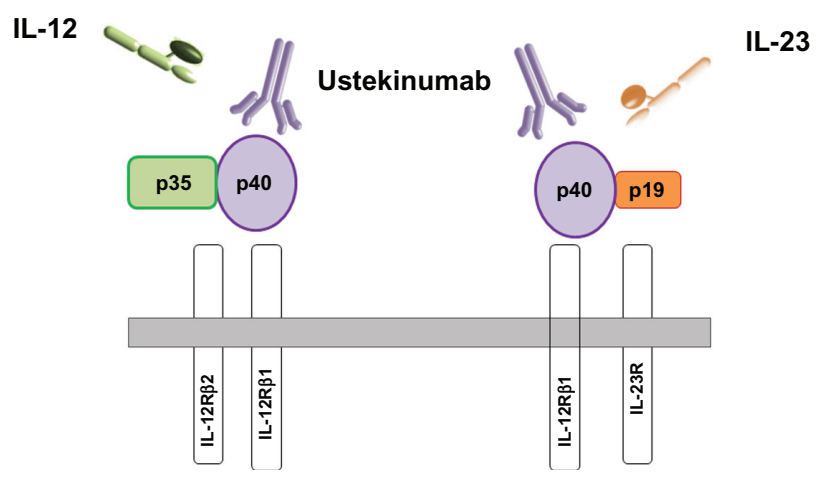

Figure I Interleukin (IL)- 12 and IL-23 structure and receptors.

Notes: The IL- 12 cytokine is composed of two chains, p35 and p40, which are covalently linked. $\mathrm{p} 40$ is shared by IL-23, which has another subunit, pI9. The IL- 12 receptor consists of IL-I2R $3 \mid$ and IL- I2R $\beta 2$, while the IL-23 receptor results from the association of IL-I2R $\beta \mid$ and IL-23R. Ustekinumab is a human monoclonal antibody that binds to $\mathrm{p} 40$ shared by IL-I2 and IL-23. Ustekinumab blocks the interaction of IL-I 2 and IL-23 with their receptor. function of IL-12 is to induce the production of IFN- $\gamma$ by T cells, to enhance the cytotoxicity of NK and cytotoxic T cells, and to induce the differentiation of naïve CD4+ T cells into Th- 1 cells, thus playing a role in cell-mediated immunity. ${ }^{13}$ On the other hand, IL-23 promotes the expansion and survival of Th-17 cells through its receptor and signaling pathway. It is considered that IL-23 acts as a proinflammatory mediator. ${ }^{15}$ This cytokine can induce chronic inflammation through the expansion of Th-17 cells and the secretion of Th-17 by non-T cells. Th-17 cells produce several proinflammatory cytokines such as IL-17, TNF- $\alpha$, IL-17F, IL-6, IL-21, and IL-22.4,16,17 All these mediators are involved in chronic inflammatory responses in autoimmune diseases. In addition, IL-23 has a potential role with Th-17 effector cytokines in coordinating responses against bacteria. ${ }^{12}$

IL-17 (or IL-17A) belongs to the IL-17 cytokine family that also includes IL-17B to IL-17F.,13,17 All these IL-17 family members show significant homology to IL-17 A. The predominant cellular source of IL-17 is CD4+ Th-17 cells. Other cells that produce IL-17 include NK cells, mast cells, neutrophils, and $\gamma \delta$ T cells. Th-17 cells are critical to adaptive immunity against bacterial and fungal infections and are involved in the pathogenesis of inflammatory/autoimmune diseases. ${ }^{3,17}$ Excessive IL-17 production or Th-17 activation leads to autoimmunity and chronic inflammatory response. IL-17 may activate various cell types, such as macrophages, dendritic cells, endothelial cells, fibroblasts, chondrocytes, and osteoblasts to produce numerous products with proinflammatory and/or destructive effects. In particular, IL-17 induces the release of IL-1 $\beta$, TNF- $\alpha$, IL-6, granulocyte-macrophage colonystimulating factor, chemokines (CXCL8, CXC chemokine ligand 1 and 10, CC chemokine ligand 20), growth factors, metalloproteinases, and receptor of nuclear factor kappa B ligand. ${ }^{17}$ Therefore, targeting the IL-23/Th-17 pathway is an attractive approach in the treatment of chronic IMD. 5,14

\section{Ustekinumab}

Ustekinumab (CNTO-1275, Stelara ${ }^{\circledR}$, Jansen Biotech, Inc,

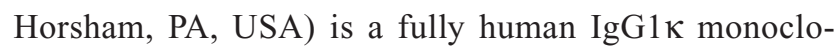
nal antibody that blocks the activity of $\mathrm{p} 40$, the subunit shared by IL-12 and IL-23. It interacts with the same epitope within the D1 domain of the p40 subunit of each cytokine. ${ }^{10,11}$ When ustekinumab is bound to $\mathrm{p} 40$, it prevents the association of both IL-12 and IL-23 to the IL-12R $\beta 1$. This results in an attenuation of immune cell activation. Ustekinumab cannot bind to IL-12 or IL-23 when these are already bound to IL-12R $\beta 1$. Thus, ustekinumab has no antibody- or complement-dependent cytotoxicity. It is given 
subcutaneously at a dose of $45 \mathrm{mg}$ (or $90 \mathrm{mg}$ for patients with a bodyweight greater than $100 \mathrm{~kg}$ ). Its half-life is around 3 weeks (range: $15-32$ days). ${ }^{11}$

\section{Ustekinumab in the treatment of psoriasis \\ IL-23/Th- I 7 pathway in psoriasis}

Psoriasis is a common chronic immune-mediated epithelial inflammatory disease characterized by keratinocyte proliferation. A dense cellular infiltrate composed of memory T cells with high IFN- $\gamma$ expression is observed in skin lesions. IL-12 is implicated in the pathogenesis of psoriasis as it induces a Th-1 response with production of IFN- $\gamma$ and homing of T cells within the skin. ${ }^{18}$ IL-12 expression may induce proliferation and activation of CD4-naïve T cells into Th-1 cells and NK cells, to produce inflammatory cytokines such as TNF- $\alpha$. In parallel, it is now evident that IL-23 also plays a crucial role in psoriasis. IL-23 activates macrophages and maintains chronic inflammation via the induction of Th-17 cells. IL-23 expression is significantly increased in the skin of patients with psoriasis, especially in psoriatic lesions compared with biopsies of normal adjacent skin. ${ }^{19}$ Monocytes from patients with psoriasis produce high levels of IL-23. IL-23 induces the expansion of Th-17 cells that produce IL-17, which in turn stimulates keratinocyte proliferation. ${ }^{5}$ In parallel, studies on transgenic mice suggest that IL-23 rather than IL-12 plays a role in psoriasis. Indeed, IL-12p40 transgenic mice constitutively produced IL-23 but not IL-12 in keratinocytes. Injections of IL-23 in nontransgenic mice induced an inflammatory skin disease similar to that of IL-12p40 transgenic mice.

\section{Clinical studies of ustekinumab in psoriasis}

A large program of clinical development has investigated the use of ustekinumab in patients with psoriasis in Phase II and III studies. ${ }^{9,11,20}$ In a Phase II, double-blind, placebocontrolled trial of ustekinumab in 320 patients with moderate to severe psoriasis, the percentage of patients who reached the primary endpoint (a 75\% reduction in the Psoriasis Area and Severity Index score [PASI75]) was higher in the two ustekinumab groups (subcutaneous [SC] ustekinumab $45 \mathrm{mg}$ and $90 \mathrm{mg}$ ) compared with the placebo group (52\%-81\% for the ustekinumab groups, versus $2 \%$ in the placebo group; $P<0.001$ for each). ${ }^{20}$

Two Phase III studies, PHOENIX 1 and PHOENIX 2 , were then conducted to evaluate the clinical efficacy of ustekinumab at doses of $45 \mathrm{mg}$ and $90 \mathrm{mg}$ for the treatment of moderate to severe psoriasis. ${ }^{21,22}$ There were 3 phases in each study: a 12-week placebo-controlled phase, then a 28- or 40-week placebo crossover phase, and finally a randomized withdrawal phase (weeks 40-76) in PHOENIX 1, and a randomized dose-intensification phase (weeks 28-52) in PHOENIX 2. In the PHOENIX 1 trial, 766 patients were randomized to receive ustekinumab either $45 \mathrm{mg}$ or $90 \mathrm{mg} \mathrm{SC}$ at weeks 0 and 4 and then at every 12 weeks, or a placebo in the placebo-controlled phase. A higher percentage of patients in the ustekinumab groups (45 $\mathrm{mg}$ and $90 \mathrm{mg}$ respectively) reached the primary endpoint (PASI 75) at week 12 compared with the placebo arm: $67.1 \%$ and $66.4 \%$ versus $3.1 \%$ $(P<0.0001)$. The clinical efficacy was rapid and observed as early as week 2. During the randomized withdrawal phase, the median time to loss of response in patients who were withdrawn from treatment was around 15 weeks. ${ }^{21}$ In PHOENIX 2, which included 1230 patients with moderate to severe psoriasis, similar results were observed, with $66.7 \%$ and $75.7 \%$ of PASI-75 responders in the ustekinumab $45 \mathrm{mg}$ and $90 \mathrm{mg}$ groups respectively, compared with $3.7 \%$ in the placebo group $(P<0.0001) .{ }^{22}$ Again, the onset of improvement was rapid and observed in the second week after starting ustekinumab. Predictive factors for partial response to ustekinumab were identified in this trial and included high bodyweight, previous inadequate response to more than one biological agent, long duration of psoriasis, and history of PsA. These two trials demonstrated that ustekinumab $45 \mathrm{mg}$ or $90 \mathrm{mg}$ every 12 weeks is effective for the treatment of moderate to severe psoriasis.

In another Phase III trial, ustekinumab and etanercept were compared head-to-head in patients with moderate to severe psoriasis. ${ }^{23}$ In this study, 903 patients were randomized to receive SC ustekinumab $45 \mathrm{mg}$ or $90 \mathrm{mg}$ at week 0 and 4, or etanercept $50 \mathrm{mg}$ twice weekly for 12 weeks. PASI-75 was achieved in $67.5 \%$ and $73.8 \%$ of patients receiving ustekinumab $45 \mathrm{mg}$ or $90 \mathrm{mg}$, compared with $56.8 \%$ of patients with etanercept $(P=0.01$ and $P<0.001$, respectively). These results demonstrated the superiority of ustekinumab over etanercept in the treatment of moderate to severe psoriasis, as evaluated by PASI 75 over a 12-week period (Table 1).

\section{Ustekinumab in the treatment of psoriatic arthritis}

\section{IL-23/Th-17 pathway in psoriatic arthritis}

A substantial proportion of patients with psoriasis also show joint manifestations, a condition known as PsA. Patients with PsA have increased serum levels of the p40 subunit, suggesting potential therapeutic benefits for ustekinumab in 
Table I Clinical studies of ustekinumab in psoriasis, psoriatic arthritis, Crohn's disease, and multiple sclerosis

\begin{tabular}{|c|c|c|c|c|}
\hline Study & $\begin{array}{l}\text { Immune-mediated } \\
\text { disease }\end{array}$ & Study design & Primary endpoint & Results \\
\hline Krueger et $\mathrm{al}^{20}$ & Psoriasis & $\begin{array}{l}\text { Phase II randomized placebo- } \\
\text { controlled study }\end{array}$ & PASI75 at week 12 & $\begin{array}{l}\text { Ustekinumab: } 52 \%-81 \% \\
\text { Placebo: } 2 \%\end{array}$ \\
\hline $\begin{array}{l}\text { Leonardi et }^{21}{ }^{21} \\
(\text { PHOENIX I) }\end{array}$ & Psoriasis & $\begin{array}{l}\text { Phase III, randomized, double- } \\
\text { blind, parallel-group, placebo- } \\
\text { controlled study }\end{array}$ & PASI75 at week 12 & $\begin{array}{l}\text { Ustekinumab: } 67 \% \\
\text { Placebo: } 3 \%\end{array}$ \\
\hline $\begin{array}{l}\text { Papp et } \mathrm{a}^{22} \\
(\mathrm{PHOENIX} 2)\end{array}$ & Psoriasis & $\begin{array}{l}\text { Phase III randomized, double- } \\
\text { blind, parallel-group, } \\
\text { placebo-controlled study }\end{array}$ & PASI75 at week 12 & $\begin{array}{l}\text { Ustekinumab: } 67 \%-76 \% \\
\text { Placebo: } 4 \%\end{array}$ \\
\hline $\begin{array}{l}\text { Griffiths et al }{ }^{23} \\
\text { (ACCEPT) }\end{array}$ & Psoriasis & $\begin{array}{l}\text { Phase III head to head } \\
\text { comparative study }\end{array}$ & PASI75 at week I2 & $\begin{array}{l}\text { Ustekinumab: } 68 \%-74 \% \\
\text { Etanercept: } 57 \%\end{array}$ \\
\hline Gottlieb et $\mathrm{a}^{25}$ & Psoriatic arthritis & $\begin{array}{l}\text { Phase II randomized, } \\
\text { placebo crossover study }\end{array}$ & ACR20 at week 12 & $\begin{array}{l}\text { Group I (ustekinumab then placebo) } \\
\text { versus group } 2 \text { (placebo then } \\
\text { ustekinumab) } 42 \% \text { versus I } 4 \%\end{array}$ \\
\hline Sandborn et $\mathrm{al}^{31}$ & Crohn's disease & $\begin{array}{l}\text { Phase II randomized, } \\
\text { placebo crossover study }\end{array}$ & $\begin{array}{l}\text { Clinical response according } \\
\text { to CDAl at week } 8\end{array}$ & $\begin{array}{l}\text { Ustekinumab: } 49 \% \\
\text { Placebo: } 40 \%\end{array}$ \\
\hline Sandborn et al ${ }^{12}$ & Crohn's disease & $\begin{array}{l}\text { Phase III randomized, } \\
\text { placebo-controlled study }\end{array}$ & $\begin{array}{l}\text { Clinical response according } \\
\text { to CDAl at week } 6\end{array}$ & $\begin{array}{l}\text { Ustekinumab: } 36 \%-39 \% \\
\text { Placebo: } 23.5 \%\end{array}$ \\
\hline Segal et $\mathrm{a}^{35}$ & Multiple sclerosis & $\begin{array}{l}\text { Phase II randomized, } \\
\text { placebo-controlled study }\end{array}$ & $\begin{array}{l}\text { New gadolinium enhancing } \\
\text { TI-weighted brain MRI } \\
\text { lesions at week } 23\end{array}$ & $\begin{array}{l}\text { No difference between any } \\
\text { ustekinumab groups versus placebo }\end{array}$ \\
\hline
\end{tabular}

Abbreviations: ACR20, American College of Rheumatology 20\% improvement criteria; CDAI, Crohn's Disease Activity Index; MRI, magnetic resonance imaging; PASI75, a $75 \%$ reduction in the Psoriasis Area and Severity Index score.

the treatment of PsA. ${ }^{24}$ In animal models of chronic arthritis, IL-12 and IL-23 have been shown to mediate collageninduced arthritis. Conversely, mice deficient in IL-12 and IL-23 or IL-23 alone are protected from arthritis when immunized with collagen. IL-23 induced IL-17 production, which plays a role in bone destruction mechanisms of arthritis. Thus, it is believed that IL-23 is an important contributor to joint inflammation in PsA. ${ }^{5,9}$

\section{Clinical efficacy of ustekinumab in psoriatic arthritis} Ustekinumab was evaluated in a 36-week randomized, placebo-controlled, crossover trial. ${ }^{25}$ In this study, 146 patients with active $\mathrm{PsA}$ received SC ustekinumab (90 mg or $63 \mathrm{mg}$ ) every week for 4 weeks, and then a placebo at weeks 12 and 16; or placebo for the first 4 weeks and then ustekinumab at weeks 12 and 16 . The primary endpoint, namely the percentage of American College of Rheumatology $20 \%$ improvement criteria (ACR20) responders at week 12 , was achieved by $42 \%$ in the ustekinumab group and $14 \%$ in the placebo group $(P=0.0002)$. In addition, PASI75 was achieved by $52 \%$ and $5 \%$ in the ustekinumab and placebo groups respectively (Table 1). Two recent studies have confirmed these results with ustekinumab in PsA, namely the PSUMMIT $1^{26}$ and PSUMMIT ${ }^{27}$ studies. In these two large randomized, placebo-controlled Phase III trials, 615 patients (in PSUMMIT1) and 312 patients (in PSUMMIT2) were randomized to receive ustekinumab (45 or $90 \mathrm{mg} \mathrm{SC}$ ) at weeks 0 and 4, and every 12 weeks, or a placebo. Patients were required to have active disease despite traditional treatments in PSUMMIT1, and despite traditional treatments or anti-TNF- $\alpha$ agents in PSUMMIT2. The primary endpoint was the rate of ACR responders at week 16 (PSUMMIT1) or week 24 (PSUMMIT2). The results showed a higher proportion of responders in the ustekinumab arms in both studies compared with placebo (ustekinumab $45 \mathrm{mg}$ versus $90 \mathrm{mg}$ versus placebo: PSUMMIT1, 42.4\% versus $49.5 \%$ versus $22.8 \%$; PSUMMIT2, $43.7 \%$ versus $43.8 \%$ versus $20.2 \%$; all $P<0.001)$.

\section{Ustekinumab in the treatment of $C D$ IL-23/Th- I7 pathway in CD}

$\mathrm{CD}$ is a chronic IMD characterized by inflammation of the gastrointestinal tract. CD is characterized by a deregulation of Th- 1 cytokine production, with IL-12 playing a role. However, a wide range of other cytokines is found in the intestines of patients with CD, including IFN- $\gamma$, TNF- $\alpha$, IL-1 $\beta$, and IL-6. ${ }^{28}$ IL-23 and IL-17 are also overexpressed in the gut of patients with CD. IL-23 mRNA is highly expressed in biopsy specimens of CD patients, and serum levels of IL-17 are elevated in patients with active disease compared with those with inactive disease. ${ }^{29}$ In animal models of colitis, treatment with ustekinumab improved intestinal inflammation. ${ }^{30}$ In addition, 
an association between the IL-23R gene polymorphism and CD has been described. ${ }^{5,15}$

\section{Clinical efficacy of ustekinumab in CD}

Ustekinumab was evaluated for the treatment of moderate to severe $\mathrm{CD}$ in a randomized, placebo-controlled trial that included 104 patients. ${ }^{31}$ In this study, ustekinumab was given subcutaneously (90 mg) or intravenously (IV) (4 or $5 \mathrm{mg} / \mathrm{kg}$ ). There were $2 \mathrm{CD}$ populations: the first comprised patients who had previously received conventional or biologic therapy (population 1), and the second comprised patients who did not respond to infliximab (population 2). In the first population, patients were randomized to receive SC placebo at weeks $0,1,2$, and 3, followed by ustekinumab $90 \mathrm{mg}$ at weeks $8,9,10$, and 11 ; or SC ustekinumab at weeks 0,1 , 2 , and 3 followed by placebo at weeks $8,9,10$, and 11 ; or IV placebo at week 0 followed by ustekinumab $4.5 \mathrm{mg} / \mathrm{kg}$ at week 8 ; or IV ustekinumab $4.5 \mathrm{mg} / \mathrm{kg}$ at week 0 followed by placebo at week 8 . In this first population, compared with placebo, ustekinumab groups showed a higher rate of clinical response at week 4 as evaluated by the Crohn's Disease Activity Index (CDAI) (ustekinumab versus placebo: $52.9 \%$ versus $30.2 \%$, respectively; $P=0.02$ ). However, at week 8 , the percentage of responders was similar in the ustekinumab and placebo groups ( $49 \%$ versus $39.6 \% ; P=0.34$ ). In a subgroup analysis of 49 patients from population 1 who had previously received infliximab, clinical response at weeks $2,4,6$, and 8 was higher in ustekinumab-treated patients than in placebotreated patients $(55 \%-59 \%$ versus $15 \%-26 \% ; P<0.05)$. On the other hand, clinical response was obtained by $43 \%$ (SC ustekinumab) and 54\% (IV ustekinumab) of patients in the open-label study (population 2), which was similar to those observed in the first population. The authors concluded that the ustekinumab response was more evident in patients who had previously received infliximab. ${ }^{31}$

Another trial evaluated the clinical efficacy of ustekinumab in patients with CD resistant to TNF- $\alpha$ inhibitors. ${ }^{32}$ In an induction phase, patients were randomized to receive IV ustekinumab at a dose of 1,3 , or $6 \mathrm{mg} / \mathrm{kg}$ or placebo at week 0 . In the maintenance phase, patients responding to ustekinumab at week 8 underwent second randomization to receive SC ustekinumab $90 \mathrm{mg}$ or placebo at weeks 8 and 16 . The clinical response as evaluated by the CDAI was better in the ustekinumab group $(1,3$, and $6 \mathrm{mg} / \mathrm{kg})$ compared with placebo: $36.6 \%, 34.1 \%$, and $39.7 \%$ versus $23.5 \%$, but results were only significant at the $6 \mathrm{mg} / \mathrm{kg}$ dose $(P=0.005)$. Maintenance therapy resulted in a significantly increased rate of clinical remission and response in the ustekinumab group compared with placebo. These results demonstrated the clinical efficacy of ustekinumab as induction therapy in CD resistant to TNF- $\alpha$ inhibitors. Furthermore, patients who initially responded to ustekinumab also had significantly increased rates of response to this treatment when given as maintenance therapy (Table 1).

\section{Ustekinumab in the treatment of multiple sclerosis}

\section{IL-23/Th- 7 pathway in MS}

MS is a chronic IMD that affects the central nervous system. Chronic inflammation in the brain results in destruction of myelin sheaths, leading to clinical manifestation. It has been demonstrated that the IL-23/Th-17 pathway is involved in the animal model of MS, ie, experimental allergic encephalomyelitis (EAE). ${ }^{7,15}$ It was first demonstrated that IL-23 was a key cytokine in EAE, which was considered to be a Th-1-related disease, with IL-12 and IFN- $\gamma$ playing a major role. However, mice lacking the IL-12p35 chain may develop EAE, whereas mice lacking the IL-23p19 subunit do not, demonstrating the direct effect of IL-23 in inducing EAE. ${ }^{33}$ In addition, levels of IL-17 correlate with disease severity in EAE. Monocyte-derived dendritic cells from patients with MS produced more IL-23 than healthy controls, and a higher percentage of peripheral blood or cerebrospinal fluid monocytes of MS patients were positive for IL-17 mRNA compared with healthy controls. Stimulated CD4+ T cells from MS patients produced more IL-17 compared with T cells from healthy subjects. ${ }^{34}$ However, both Th-1 and Th-17 subsets contribute to the disease, and it is difficult to differentiate the respective role of each pathway.

\section{Clinical efficacy of ustekinumab in MS}

Ustekinumab has been evaluated in patients with remittingrelapsing MS in a randomized Phase 2 clinical trial. ${ }^{35}$ In total, 249 patients were assigned to placebo or four different doses of ustekinumab (27-180 mg). Drug-treated groups received SC ustekinumab at a dose of 27,90 , or $180 \mathrm{mg}$ every week between weeks 0 and 3 , then every four weeks, while the last group received $90 \mathrm{mg}$ every week between weeks 0 and 3 , then every eight weeks until week 19. Efficacy was evaluated by the number of contrast-enhancing cranial MRI lesions. The results showed no difference between the ustekinumab and placebo groups. One potential explanation for these negative results is that the patients included in the study had chronic disease of long duration, and the biological agent under study may not have crossed the blood-brain barrier (Table 1). 


\section{Safety data on ustekinumab}

Safety data concerning ustekinumab came from Phase II and III studies in the different chronic IMDs. ${ }^{11,28}$ All trials were designed to have a placebo-controlled phase, but some were followed by long-term therapy through 5 years (PHOENIX 1). ${ }^{21}$ The safety of ustekinumab has thus been evaluated in more than 3000 patients overall. Safety findings were largely documented in patients with moderate to severe psoriasis and available through week 36 (Phase II trial), ${ }^{20}$ week 52 (PHOENIX 2), ${ }^{22}$ week 64 (ACCEPT), ${ }^{23}$ and week 76 (PHOENIX 1). ${ }^{21}$ In patients with PsA, CD, or MS, safety findings were limited to follow-up periods ranging from 12 to 37 weeks. ${ }^{25,31,32}$ During the placebo-controlled period in the psoriasis trials, adverse events were reported in 50.4\% of patients in the placebo group and between $51.6 \%$ and $57.6 \%$ of patients in the ustekinumab group (at both doses, ie, 90 and $45 \mathrm{mg}$ ). ${ }^{11}$ Most adverse events were mild and did not require treatment withdrawal. The most frequent adverse events were respiratory tract infections including nasopharyngitis. Other frequently reported adverse events were dizziness, myalgia, injection-site reaction, diarrhea, and pharyngeal pain. ${ }^{11}$ Injection site reactions were more commonly observed with ustekinumab $45 \mathrm{mg}$ (3.4\%) or $90 \mathrm{mg}$ (4\%) than placebo (1.1\%). Infections were reported in $23.2 \%$ of placebo-treated patients compared with $27 \%$ of patients in the ustekinumab $45 \mathrm{mg}$ group and $24.1 \%$ of patients in the $90 \mathrm{mg}$ group. ${ }^{11,28}$ Serious adverse events were observed in similar proportions in each patient group $(1.4 \%, 1.6 \%$, and $1.4 \%$ of patients in the placebo, ustekinumab $45 \mathrm{mg}$ and $90 \mathrm{mg}$ groups respectively). Cardiovascular events were observed, with an incidence of major adverse cardiovascular events of 0.61 per 100 patient-years for ustekinumab-treated patients versus 0.55 for placebo-treated patients; the difference was not significant. Injection site reactions were reported by $1 \%-2 \%$ of patients. There was no increased risk of infection, especially tuberculosis. The rate of malignancies was comparable between ustekinumab and placebo-treated patients. The risk/safety profile of ustekinumab in psoriasis thus seems favorable. ${ }^{5,11,28}$

In the PsA trials, ustekinumab was well tolerated. Infections remained the most common adverse event. No cases of tuberculosis or opportunistic infections were observed. ${ }^{25-27}$

In the study of ustekinumab in $\mathrm{CD}, 6 \%$ of patients experienced one or more serious adverse event in population 1 , and one disseminated histoplasmosis occurred in population 2 of this trial. ${ }^{31}$ In the induction and maintenance therapy of ustekinumab in refractory $\mathrm{CD}$, serious infection occurred in seven patients (including six under ustekinumab) during induction and in eleven (including four under ustekinumab) during the maintenance phase. ${ }^{32}$

Ustekinumab treatment was well tolerated by patients with MS. Again, the most frequent adverse event was infection, including upper respiratory tract infection and nasopharyngitis. Other common adverse events were injection site reactions, headache, and fatigue. ${ }^{35}$

The long-term safety profile of ustekinumab was recently studied in a pooled analysis of psoriasis trials (including the Phase II, PHOENIX and ACCEPT studies). ${ }^{36,37}$ In these trials, a total of 1852 patients were exposed to ustekinumab for at least 1 year 1247 patients for at least 2 years, and 157 patients for at least 3 years. The results showed that common adverse events observed with long-term use were similar to those observed during the placebo-controlled period, ie, nasopharyngitis, upper respiratory tract infections, and headache. There was no dose-response for rates of adverse events including infections, atopic diseases, or serious adverse events. Adverse events remained stable over time or tended to decrease. ${ }^{36}$ The most common serious adverse events with long-term use included serious infections (estimated at 0.6 and 1.4 events per 100 patient-years in the ustekinumab 45 and $90 \mathrm{mg}$ groups, respectively). However, when compared with a US psoriasis population treated with conventional systemic agents, the rates of serious infections in the longterm (45 or $90 \mathrm{mg}$ ) ustekinumab exposure groups were not increased ${ }^{37}$ Cardiac disorders were the second most frequent serious adverse event with a rate of 0.8 and 1.3 events per 100 patient-years (in the ustekinumab 45 and $90 \mathrm{mg}$ groups, respectively). Malignancies (excluding non-melanoma skin cancers) were observed at a rate of 0.7 and 0.5 events per 100 patient-years in the ustekinumab 45 and $90 \mathrm{mg}$ groups, respectively. The incidence of malignancies other than non-melanoma skin cancer up to 3 years of follow up was comparable between ustekinumab-exposed psoriatic patients and the general US population, with a standardized incidence ratio of 1.05 (95\% confidence interval [CI] 0.69-1.53). ${ }^{37}$ Interestingly, no cases of tuberculosis were reported. One case of reversible posterior leukoencephalopathy syndrome was reported during the PHOENIX 2 trial. ${ }^{22}$ No changes in routine laboratory parameters during ustekinumab treatment were observed and rates of ustekinumab antibodies across the psoriasis Phase III studies were low.

A recent meta-analysis of randomized controlled trials evaluated the specific risk for major cardiovascular events (myocardial infarction, cerebrovascular accident, or cardiovascular death) in patients with psoriasis receiving ustekinumab (or briakinumab, another anti-IL-12/23p40 antibody). ${ }^{38}$ The 
results of this analysis suggest the possible existence of a higher risk of major cardiovascular events in patients treated by anti IL-12/23p40 antibody compared with placebo (odds ratio [OR] 4.23; 95\% CI 1.07-16.75; $P=0.04$ ).

Finally, exceptional events have been reported, such as paradoxical flare of psoriasis reported in one patient receiving ustekinumab for PsA, ${ }^{39}$ or alternatively, development of inflammatory arthritis in two patients following ustekinumab treatment for psoriasis. ${ }^{40}$

\section{Ustekinumab, quality of life, and patient acceptability}

The effect of ustekinumab on health-related quality of life (HR-QOL) was examined as a secondary endpoint in certain psoriasis studies. ${ }^{5,8,11}$ The effects of psoriatic treatment on HR-QOL was evaluated in the two PHOENIX trials using the change from baseline in Dermatology Life Quality Index (DLQI). ${ }^{21,22}$ General HR-QOL was also evaluated by means of medical outcomes on the study short form-36 (SF-36) in the PHOENIX 1 study. ${ }^{41}$ Sexual difficulties associated with psoriasis based on DLQI questionnaires were also evaluated in a pooled analysis of both PHOENIX trials. The hospital anxiety and depression scale (HADS) was used for the evaluation of change in psychiatric symptoms under ustekinumab in PHOENIX 2. ${ }^{42}$ Finally, work productivity was also examined by patients using a work limitation questionnaire (WLQ) in this trial.

The effect of ustekinumab on health assessment questionnaire (HAQ) and DLQI was also examined during the clinical trials in PsA. ${ }^{25}$ Conversely, there was no specific assessment of these secondary endpoints in the studies evaluating the efficacy of ustekinumab in patients with CD or MS.

Ustekinumab improved significantly HR-QOL as assessed by DLQI at 12 weeks in the PHOENIX trials. ${ }^{21,22}$ Similarly SF-36 scores were improved in the ustekinumab 45 and $90 \mathrm{mg}$ groups compared with placebo in the PHOENIX 1 study, notably the physical and mental health dimensions. ${ }^{41}$ Patient-reported symptoms of anxiety and depression were also improved under ustekinumab in PHOENIX 2: patients achieved greater improvements from baseline in both HADSanxiety and HADS-depression scores following 12 weeks treatment with ustekinumab than with placebo. ${ }^{42}$ Work productivity and the number of work days missed were also improved with ustekinumab treatment in the PHOENIX 2 trial. Lastly, ustekinumab was also shown to be effective in improving sexual difficulties in the PHOENIX trials. ${ }^{43}$

In patients with PsA, improvements in HR-QOL also favored ustekinumab treatment. At week 12, there was a significantly greater percentage improvement from baseline in HAQ score with ustekinumab than in the placebo group. Similarly, the improvement in DLQI observed in patients with an affected body surface area greater than 3\% was also significantly greater with ustekinumab than in patients receiving placebo. ${ }^{25}$

To date, there is no specific data available regarding patient preferences and acceptability of ustekinumab treatment. Ustekinumab is currently licensed in the USA for the treatment of adult patients with moderate to severe plaque psoriasis who are candidates for phototherapy or systemic treatment. In Europe, it is indicated for patients who failed to respond or have a contraindication to, or are intolerant of, other systemic therapies, including cyclosporin, methotrexate, or psoralen plus phototherapy. ${ }^{10}$ The treatment is given as a SC injection at a dose of $45 \mathrm{mg}$ for patients weighing $\leq 100 \mathrm{~kg}$ and $90 \mathrm{mg}$ for those weighing $>100 \mathrm{~kg}$. The therapeutic regimen is one injection at week 0 and week 4, and then every 12 weeks. Ustekinumab is an expensive drug, costing around $€ 3200$ (US\$4000) per vial. The annual cost for six injections is therefore around $€ 20,000$ (US\$25,000) per patient.

When administered at recommended doses, patient acceptability of ustekinumab is high. In fact, the discontinuation rate during Phase II and III trials in psoriasis was very low, with rates of only $1.1 \%$ and $1.4 \%$ of patients receiving ustekinumab 45 and $90 \mathrm{mg}$ respectively, compared with a $1.9 \%$ discontinuation rate under placebo. ${ }^{11,36}$ These discontinuations were related to an adverse event, and did not stem from patient discomfort induced by injection site reactions, for instance.

Overall, ustekinumab is effective and improves clinical symptoms of psoriasis as evaluated by PASI75. It is also effective in improving quality of life outcomes and has a good safety profile. Its clinical efficacy is maintained for up to 3 years, and no specific cause for alarm has been observed with its long-term use. For all these reasons, ustekinumab acceptability may be considered high in patients with moderate to severe plaque psoriasis. Alternative biological therapies for psoriasis include TNF- $\alpha$ antagonists. ${ }^{1}$ Ustekinumab was more effective than etanercept in improving the symptoms of moderate to severe psoriasis in the ACCEPT trial. ${ }^{23}$ Similarly, the maintenance therapy regimen of ustekinumab compares favorably with other biological agents in that one SC injection is required every 12 weeks, compared with etanercept, which is given once weekly. This suggests that patients with psoriasis may presumably prefer ustekinumab to etanercept. The place of ustekinumab in the management of moderate to severe psoriasis remains debated, and requires additional 
head-to-head clinical trials comparing the efficacy of the various biological agents in the management of this chronic IMD. International guidelines are still under development, and certain professional dermatology societies (eg, American Academy of Dermatology or Canadian Dermatology Association) consider that all biological agents may be appropriate as first-line therapy, whereas others (ie, British Association of Dermatologists) recommend the use of biological agents in patients who have failed to respond to, or are intolerant of, or have a contraindication to phototherapy or conventional systemic drugs. ${ }^{11}$ There are no available data for patient preferences to one biological agent (ustekinumab or TNF- $\alpha$ antagonists) in the treatment of PsA.

\section{Conclusion}

Subcutaneous ustekinumab 45 or $90 \mathrm{mg}$ has been shown to be effective in, and is currently licensed for the treatment of moderate to severe plaque psoriasis. It is also effective in patients with active PsA who did not respond to conventional drugs or TNF- $\alpha$ antagonists and in patients with refractory CD. In psoriasis, ustekinumab may benefit patients who do not respond to, or are intolerant of, other conventional therapies. Ustekinumab appears to be well tolerated and easy to use, suggesting high patient acceptability. Additional data are necessary for its long-term administration in psoriasis, especially regarding the cardiovascular safety profile. Headto-head trials comparing ustekinumab to biological agents other than etanercept are required to better define its position among the therapeutic armamentarium in the treatment of psoriasis. Similarly, the place of ustekinumab in the treatment of $\mathrm{CD}$ also requires further investigation.

\section{Acknowledgments}

The authors are indebted to Mrs Fiona Ecarnot MSc, EA3920, Department of Cardiology, University Hospital of Besançon, France for her help in preparing the manuscript.

\section{Disclosure}

The authors have no conflicts of interest that are relevant to the content of this review. No author is currently bound by any financial agreements regarding the product discussed in this article.

\section{References}

1. Tobin AM, Kirby B. TNF alpha inhibitors in the treatment of psoriasis and psoriatic arthritis. Bio Drugs. 2005;19(1):47-57.

2. Peyrin-Biroulet L, Deltenre P, de Suray N, Branche J, Sandborn WJ, Colombel JF. Efficacy and safety of tumor necrosis factor antagonists in Crohn's disease: meta-analysis of placebo-controlled trials. Clin Gastroenterol Hepatol. 2008;6(6):644-653.
3. Miossec P, Korn T, Kuchroo VK. Interleukin-17 and type 17 helper T cells. N Engl J Med. 2009;361(9):888-898.

4. Romagnani R. Human Th17 cells. Arthritis Res Ther. 2008; 10(2):206.

5. Toussirot E. The IL-23/Th17 pathway as a therapeutic target in chronic inflammatory diseases. Inflamm Allergy Drugs Targets. 2012;11(2):159-168.

6. McGeachy MJ, Cua DJ. The link between IL-23 and Th17 cell-mediated immune pathologies. Semin Immunol. 2007;19(6):372-376.

7. Langrish CL, Chen Y, Blumenschein WM, et al. IL-23 drives a pathogenic $\mathrm{T}$ cell population that induces autoimmune inflammation. $J$ Exp Med. 2005;201(1):233-240.

8. Elliott M, Benson J, Blank M, et al. Ustekinumab: lessons learned from targeting interleukin-12/23p40 in immune-mediated diseases. Ann NY Acad Sci. 2009;1182:97-110.

9. Kurzeja M, Rudnicka L, Olszewska M. New interleukin-23 pathway inhibitors in dermatology. Am J Clin Dermatol. 2011;12(2):113-125.

10. Cingoz O. Ustekinumab. MAbs. 2009;1(3):216-221.

11. Croxtall JD. Ustekinumab: a review of its use in the management of moderate to severe plaque psoriasis. Drugs. 2011;71(13):1733-1753.

12. Gee K, Guzzo C, Che Mat NF, Ma W, Kumar A. The IL-12 family of cytokines in infection, inflammation and autoimmune disorders. Inflam Allergy-Drug Targets. 2009;8(1):40-52.

13. Kikly R, Liu L, Na S, Sedwick JD. The IL-23/Th17 axis: therapeutic target for autoimmune inflammation. Curr Opin Immunol. 2006;18(6): 670-675.

14. Iwakura Y, Ishigame H. The IL-23/IL-17 axis in inflammation. $J$ Clin Invest. 2006;116(5):1218-1222.

15. Tang C, Chen S, Qian H, Huanh W. IL-23: as a drug target for autoimmune inflammatory diseases. Immunology. 2012;135(2):112-124.

16. Miossec P. IL-17 and Th17 cells in human inflammatory diseases. Microbes Infections. 2009;11(5):625-630.

17. Pappu R, Ramirez-Carrozzi V, Sambandam A. The interleukin-17 cytokine family: critical players in host defence and inflammatory diseases. Immunology. 2011;134(1):8-16.

18. Shaker OG, Moustafa W, Essmat S, Abdel-Halim M, El-Komy M. The role of interleukin-12 in the pathogenesis of psoriasis. Clin Biochem. 2006;39(2):119-125.

19. Lee E, Trepicchio WL, Oestreicher JL, et al. Increased expression of interleukin $23 \mathrm{p} 19$ and p40 in lesional skin of patients with psoriasis vulgaris. $J$ Exp Med. 2004;199(1):125-130.

20. Krueger GG, Langley RG, Leonardi C, et al. A human interleukin $12 / 23$ monoclonal antibody for the treatment of psoriasis. $N$ Engl $J$ Med. 2007;356(6):580-592

21. Leonardi CL, Kimball AB, Papp KA, et al. Efficacy and safety of ustekinumab, a human interleukin-12/23 monoclonal antibody in patients with psoriasis: 76 week results from a randomised, doubleblind, placebo-controlled trial (PHOENIX 1). Lancet. 2008;371(9625): 1665-1674.

22. Papp KA, Langley RG, Lebwohl M, et al. Efficacy and safety of ustekinumab, a human interleukin-12/23 monoclonal antibody in patients with psoriasis: 52 week results from a randomised, doubleblind, placebo-controlled trial (PHOENIX 2). Lancet. 2008;371(9625): $1675-1684$.

23. Griffiths CEM, Strober B, van de Kerkhof P, et al. Comparison of ustekinumab and etanercept for moderate to severe psoriasis. $N$ Engl J Med. 2010;362(2):118-128.

24. Ritchlin C, Haas-Smith SA, Hicks D, et al. Patterns of cytokine production in psoriatic synovium. J Rheumatol. 1998;25(8):1544-1552.

25. Gottlieb A, Menter A, Mendelsohn A, et al. Ustekinumab, a human interleukin-12/23 monoclonal antibody for psoriatic arthritis: randomised, double-blind, placebo-controlled, cross-over trial. Lancet. 2009;373(9664):633-640.

26. Kavanaugh A, McInnes I, Gottlieb A, et al. Ustekinumab in patients with active psoriatic arthritis: results of the phase 3 , multicentre, doubleblind, placebo-controlled Psummit I study. Arthritis Rheum. 2012; 64(Suppl 10):S1083-S1084. 
27. Ritchlin CT, Gottlieb A, McInnes I, et al. Ustekinumab in active psoriatic arthritis including patients previously treated with anti-TNF agents: results of a phase 3 , multicentre, double-blind, placebo-controlled study. Arthritis Rheum. 2012;64(Suppl 10):S1080-S1081.

28. Scherl EJ, Kumar S, Warren RU. Review on the safety and efficacy of ustekinumab. Ther Adv Gastroenterol. 2010;3(5):321-328.

29. Fujino S, Andoh A, Bamba S, et al. Increased expression of interleukin 17 in inflammatory bowel disease. Gut. 2003;52(1):65-70.

30. Elson CO, Cong Y, Weaver CT, et al. Monoclonal anti-interleukin 23 reverses active colitis in a $\mathrm{T}$ cell-mediated model in mice. Gastroenterology. 2007;132(7):2359-2370.

31. Sandborn WJ, Feagan BG, Fedorak RN, et al. A randomized trial of ustekinumab, a human interleukin-12/23 monoclonal antibody in patients with moderate to severe Crohn's disease. Gastroenterology. 2008;135(4):1130-1141.

32. Sandborn WJ, Gasink C, Gao LL, et al. Ustekinumab induction and maintenance therapy in refractory Crohn's disease. $N$ Engl J Med. 2012;367(16):1519-1528.

33. Cua D, Sherlock J, Chen Y, et al. Intereukin-23 rather than interleukin-12 is the critical cytokine for autoimmune inflammation of the brain. Nature. 2003;421(6924):744-748.

34. Chen Y, Langrish CL, McKenzie B, et al. Anti-IL-23 therapy inhibits multiple inflammatory pathways and ameliorates autoimmune encephalomyelitis. J Clin Invest. 2006;116(5):1317-1326.

35. Segal BM, Constantinescu C, Raychaudhuri A, et al. Repeated subcutaneous injections of IL-12/23 p40 neutralising antibody, ustekinumab, in patients with relapsing-remitting multiple sclerosis: a phase II, double-blind, placebo-controlled, randomised, dose ranging study. Lancet Neurol. 2008;7(9):796-804.

36. Lebwohl M, Leonardi G, Griffiths CEM, et al. Long-term safety experience of ustekinumab in patients with moderate-to-severe psoriasis (part I of II): results from analyses of general safety parameters from pooled phase 2 and 3 clinical trials. J Am Acad Dermatol. 2012;66(5):731-741.
37. Gordon KB, Papp KA, Langley RG, et al. Long-term safety experience of ustekinumab in patients with moderate to severe psoriasis (part II of II): results from analyses of infections and malignancy from pooled phase II and III clinical trials. J Am Acad Dermatol. 2012;66(5):742-751.

38. Tzellos T, Kyrgidis A, Zouboulis CC. Re-evaluation of the risk for major adverse cardiovascular events in patients treated with IL-12/23 biological agents for chronic plaque psoriasis: a meta-analysis of randomized controlled trials. J Eur Acad Dermatol Venereol. Epub March 8, 2012.

39. Puig L, Morales-Munera CE, Lopez-Ferrer A, Geli C. Ustekinumab treatment of TNF antagonist- induced paradoxical psoriasis flare in a patient with psoriatic arthritis: case report and review. Dermatology. 2012;225(1):14-17.

40. De Souza A, Ali-Shaw T, Redy SM, Fiorentino D, Strober BE. Inflammatory arthritis following ustekinumab treatment for psoriasis: a report of two cases. Br J Dermatol. 2013;168(1):210-212.

41. Lebwohl M, Papp K, Han C, et al. Ustekinumab improves health-related quality of life in patients with moderate to severe psoriasis: results from the PHOENIX I trial. Br J Dermatol. 2010;162(1):137-146.

42. Langley RG, Feldman SR, Han C, et al. Ustekinumab significantly improves symptoms of anxiety, depression, and skin related quality of life in patients with moderate to severe psoriasis: results from a randomized, double-blind, placebo controlled phase III trial. J Am Acad Dermatol. 2010;63(3):457-465.

43. Guenther L, Han C, Szapary P, et al. Impact of ustekinumab on health related quality of life and sexual difficulties associated with psoriasis: results from two phase III clinical trials. J Eur Acad Dermatol Venereol. 2011;25(7):851-857.
Patient Preference and Adherence

\section{Publish your work in this journal}

Patient Preference and Adherence is an international, peer-reviewed, open access journal focusing on the growing importance of patient preference and adherence throughout the therapeutic continuum. Patient satisfaction, acceptability, quality of life, compliance, persistence and their role in developing new therapeutic modalities and compounds to

\section{Dovepress}

optimize clinical outcomes for existing disease states are major areas of interest. This journal has been accepted for indexing on PubMed Central The manuscript management system is completely online and includes a very quick and fair peer-review system. Visit http://www.dovepress.com/ testimonials.php to read real quotes from published authors. 